\title{
Early results using the Atlantis anterior cervical plate system
}

\author{
Bryan Barnes M.D., Regis W. Haid, M.D., Gerald Rodts, M.D., Brian Subach, M.D., \\ AND MiChaEl KaISER, M.D. \\ Department of Neurosurgery, Emory School of Medicine, Atlanta, Georgia; and Department of \\ Neurosurgery, College of Physicians and Surgeons, Columbia University, New York, New York
}

\begin{abstract}
Object. The authors present a retrospective review of 77 patients in whom they performed anterior cervical discectomy and fusion (ACDF) in the treatment of radiculopathy and/or myelopathy. In all cases anterior interbody fusion was performed using the Atlantis locking plate system to treat the degenerative disease.

Methods. There were 41 men and 36 women (mean age 53.8 years), and 24 active cigarette smokers ( $31 \%$ ) in the group. All patients presented with signs and symptoms of cervical radiculopathy and/or myelopathy, and magnetic resonance imaging or computerized tomography myelography demonstrated evidence of radicular and/or spinal cord compression at one or more cervical levels. Thirty-one patients underwent single-level ACDF, 20 patients underwent multilevel ACDF without posterior instrumentation, in eight patients one- to four-level corpectomies were supplemented with posterior fixation, 12 patients underwent single-level corpectomy, and six patients underwent multilevel corpectomy with no posterior instrumentation. The mean follow-up period was 15.33 months; overall good-to-excellent outcome was seen in $75 \%$ of patients; osseous fusion was demonstrated in $93.5 \%$. In all patients except three, fibular allograft was used as graft material.

The degree of overall cervical lordosis was measured at the last follow up and was compared with normal values obtained in age-matched individuals. In addition, the degree of cervical lordosis at fusion levels was compared with overall cervical lordosis. In patients in all five of the aforementioned categories significantly less lordosis was demonstrated than in age-matched controls. In patients who underwent single-level ACDF, single-level corpectomy, and multilevel ACDF significantly less lordosis was observed at the fusion segment than that in the overall cervical spine.

Complications included one episode of chronic anterior wound drainage treated with intravenous antibiotic medication and one postoperative posterior wound infection, which required reoperation and intravenous antibiotic medication. Two cases $(2.6 \%)$ of anterior screw backout and/or breakage were identified. One patient died of unrelated causes within 3 months of operation.

Conclusions. These initial results indicate that use of the Atlantis plate system for anterior cervical arthrodesis produces fusion rates and clinical outcomes that are comparable with those obtained using other locking plating systems. It has the unique advantage, however, of providing the surgeon with the choice of fixed, variable, or hybrid screw constructs as a way of tailoring screw angles to individual anatomical/biomechanical needs.
\end{abstract}

KEY WORDS - anterior • cervical plate • interbody fusion • locking plate system

Anterior cervical fusion was first performed by Bailey and Badgley in 1952. ${ }^{1}$ The techniques of anterior cervical fusion were subsequently advanced by Smith and Robinson; Cloward emphasized the importance of simultaneous spinal decompression with cervical fusion procedures. At first, single-level anterior fusion procedures yielded good results, but with the efforts to correct multilevel disease the incidence of pseudarthroses and kyphotic deformities approached $40 \% .{ }^{35}$ Efforts were subsequently

Abbreviations used in this paper: $\mathrm{ACDF}=$ anterior cervical discectomy and fusion; ACP = anterior cervical plate; ANOVA = analysis of variance; $\mathrm{CT}=$ computerized tomography; $\mathrm{VB}=$ vertebral body. undertaken to produce cervical stabilization devices for multilevel anterior cervical procedures and traumatic (or potentially unstable) single-level fusions.

An anterior plate and screw internal stabilization device was first developed by Bohler in $1964 .^{2}$ During the 1980 s Caspar collaborated with the Aesculap to produce a standardized set of instruments and a plating technique. ${ }^{5}$ Many surgeons found, however, that the bicortical purchase required by the Caspar plate system was cumbersome and time consuming.

Raveh, et al., ${ }^{24}$ developed a hollow, unicortical locking screw system in which screws were locked into place by an expansion screw. This screw system provided the design basis for the current Synthes system, which was introduced in $1991 .{ }^{18}$ Since that time, several other unicorti- 
B. Barnes, et al.

TABLE 1

Summary of data obtained in 77 patients undergoing ACDF procedures for the treatment of radiculopathy and/or myelopathy*

\begin{tabular}{|c|c|c|c|c|c|c|}
\hline Characteristic & $\begin{array}{l}\text { 1-Level } \\
\text { ACDF }\end{array}$ & $\begin{array}{c}\text { Multilevel } \\
\text { ACDF }\end{array}$ & $\begin{array}{l}\text { Anterior- } \\
\text { Posterior }\end{array}$ & $\begin{array}{c}\text { 1-Level } \\
\text { Corpectomy }\end{array}$ & $\begin{array}{l}\text { Multilevel } \\
\text { Corpectomy }\end{array}$ & Total \\
\hline no. of patients & 31 & 20 & 8 & 12 & 6 & 77 \\
\hline fixed & 3 & 1 & 0 & 0 & 0 & 4 \\
\hline hybrid & 28 & 19 & 8 & 12 & 6 & 73 \\
\hline variable & 0 & 0 & 0 & 0 & 0 & 0 \\
\hline mean age (range) in yrs & $49.6(25-77)$ & $57(35-79)$ & $57.8(39-70)$ & $52.6(42-65)$ & $55(45-66)$ & $53.8(25-79)$ \\
\hline mean FU (mos) & 14.6 & 13.75 & 16.6 & 19 & 13.6 & 15.33 \\
\hline smoking $(\%)$ & 16.1 & 20 & 75 & 33 & 83 & 31.2 \\
\hline \multicolumn{7}{|l|}{ Workers' compensation } \\
\hline claims $(\%)$ & 16.1 & 5 & 37 & 41.6 & 16 & 19.5 \\
\hline male $(\%)$ & 54.8 & 60 & 63 & 41 & 33 & 53.3 \\
\hline female $(\%)$ & 45.2 & 40 & 37 & 59 & 67 & 46.7 \\
\hline fusion $(\%)$ & 93.5 & 90 & 100 & 91.6 & 100 & 93.5 \\
\hline overall cervical lordosis at $\mathrm{FU}\left({ }^{\circ}\right)$ & $9.8 \dagger$ & $11.6 \dagger$ & 7.8 & $12.6 \dagger$ & $8.9 \dagger$ & 9.5 \\
\hline segmental lordosis $\left(^{\circ}\right)$ & $3.2 \ddagger$ & $4.8 \ddagger$ & 5.4 & $2.5 \ddagger$ & 5.2 & 3.7 \\
\hline satisfactory outcome $(\%)$ & 77.4 & $65 \S$ & $63 \S$ & 91.6 & 83 & 75 \\
\hline
\end{tabular}

$* \mathrm{FU}=$ follow up.

$\dagger$ Significant difference between age-matched controls and patients.

$¥$ Significant difference between overall lordosis and lordosis at fusion segment.

$\S$ Significantly lower rate of satisfactory outcome compared with other cohorts.

cal locking screw systems have become available. Unicortical locking plate systems are now favored by most surgeons because they have yielded a lower rate of screw backout, are easier to use, and reduce the risk of spinal injury compared with bicortical nonlocking systems. ${ }^{22,27,28,31}$ Controversy still exists with regard to the added value of using a cervical plate for one-level discectomy and fusion procedures, but ACPs have been shown to increase fusion rates in single-level corpectomies and multilevel cervical procedures. ${ }^{8,10,16,32-34}$

Most systems currently available are ones in which screws are drilled into vertebrae at predetermined angles only or at variable angles only, without consideration of individual needs such as aberrant anatomy or suboptimum screw purchase.

Fusion rates and outcome data with the Atlantis plating system (Medtronic Sofamor-Danek, Memphis, TN) have not been widely reported. We present our initial experience with this system, which provides the unique option of having fixed, variable, or hybrid screw constructs, thereby allowing for the tailoring of bone screw angles and graft load sharing to individual patient needs.

\section{CLINICAL MATERIAL AND METHODS}

Between July 1998 and September 2000, 77 patients underwent anterior cervical fusion procedures ranging from single-level ACDF to four-level corpectomy with posterior fusion, in which the Atlantis ACP system was used. All procedures were performed to treat cervical radiculopathy and/or myelopathy. There were 41 men and 36 women, with a mean age of 53.8 years. There were 24 active cigarette smokers (35\%). Data were collected by chart review, review of radiographs, and follow-up clinical examination. All patients included in the study underwent a minimum of 12 months of clinical and radiographic follow up. Postoperative radiographs were reviewed by the senior author (M.K.) and the attending radiologist to determine the success of fusion, and in some cases CT scanning was conducted for supplemental verification of plain radiographic findings. All patients presented with cervical myelopathy and/or radiculopathy, and magnetic resonance imaging or CT myelography confirmed degenerative changes and compression at the appropriate level. Nonoperative therapy conducted for a minimum of 3 months after onset of symptoms failed to resolve pain in all patients. There were 31 single-level ACDF procedures, 20 multilevel ACDF procedures, 12 single-level corpectomies, six multilevel corpectomies without posterior instrumentation, and eight corpectomies with posterior supplemental instrumentation (Table 1). In all cases except three, fibular allograft was used for interbody graft; in three single-level ACDF procedures we used iliac crest autograft.

Outcomes were assessed using Odom criteria: excellent, good, fair, or poor. ${ }^{21}$ Excellent and good outcomes were considered satisfactory, whereas fair and poor outcomes were considered unsatisfactory. Patients with excellent outcomes were those in whom the following were demonstrated: a significant reduction and or cessation of pain medication usage, return to full participation in premorbid activities, and/or return to full-time work; additionally significant improvement was demonstrated in subjective pain. Patients with good outcomes were those in whom the following were shown: an improvement in subjective pain, an ability to work part time and/or partially participate in premorbid activities, and a diminished requirement for narcotic and/or analgesic medications compared with preoperative dependence. Patients with fair outcomes were those in whom the following were shown: mild improvements in subjective pain, no change in analgesic/ narcotic use, and only minimal participation in premorbid activity and/or work. Poor outcomes were defined as no reported improvement in pain or worsened pain, no participation in premorbid activities/work, and increased or same levels of narcotic/analgesic use. 


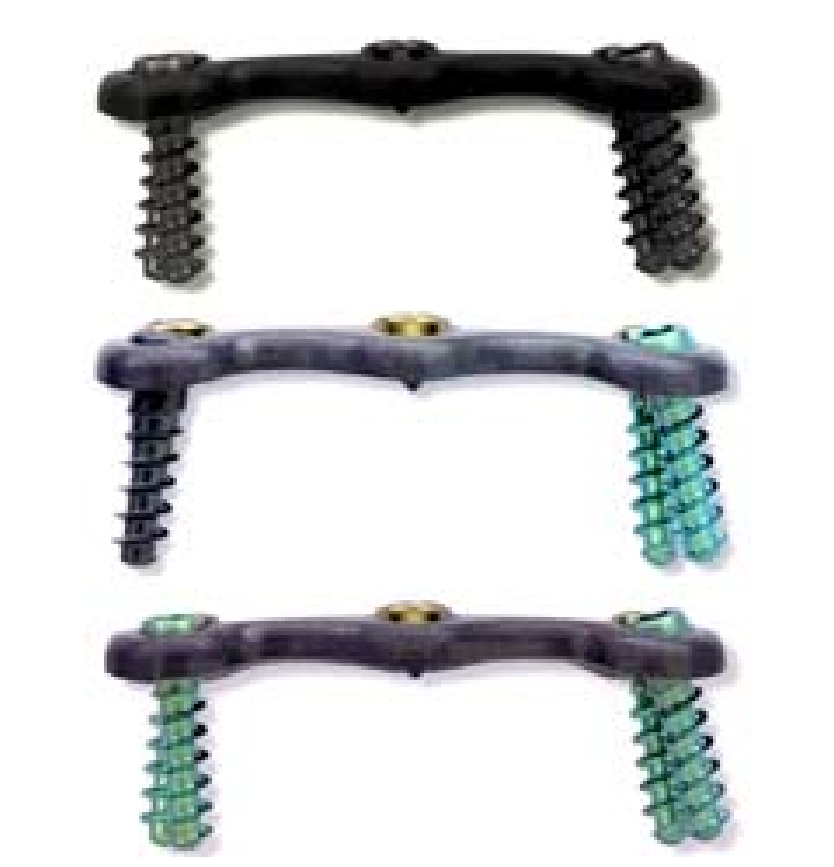

Fig. 1. Photographs showing the Atlantis ACP system constructs. Upper: Fixed construct, providing constrained system. Center: Hybrid construct in which inferior (fixed-angle) screws act as buttress while variable-angle (superior) screws rotate at the plate-screw interface. Lower: Variable construct, with rotation at both superior and inferior aspects of plate-screw interface.

Fusion was determined at follow up and was defined on cervical plain radiographs as the absence of lucency around the graft and the presence of bridging bone incorporating the bone graft. Dynamic plain cervical radiographs were used to assess stability of the constructs, and presence of instability was considered to be evidence of pseudarthrosis. In some cases CT myelography was performed to supplement plain X-ray film findings.

Patients were divided into five groups as listed in Table 1: single-level ACDF, multilevel ACDF, combined anterior-posterior fusion, single-level corpectomy, and multilevel corpectomy.

Cervical lordosis was measured using the methods reported by Gore, et al.; ${ }^{13}$ the angle formed by a line parallel to the posterior portion of the $\mathrm{VB}$ of $\mathrm{C}-2$ and a line parallel to the posterior portion of the $\mathrm{VB}$ of $\mathrm{C}-7$ was used for overall cervical lordosis. A similar method was used to calculate the lordotic angle at the level or levels involved in fusion, using a line parallel to the posterior portion of the superior $\mathrm{VB}$ in the construct and a line parallel to the posterior portion of the $\mathrm{VB}$ at the inferior portion of the construct.

Statistical analysis using SPSS for Windows was undertaken using a paired t-test for each of the five categories of fusion listed in Table 1. For each patient in each of five fusion categories, cervical lordosis at the most recent follow-up examination was calculated and compared with that in an age-matched mean. For patients who fell in age group categories for which there were no age-matched means as described by Gore, et al., ${ }^{13}$ the next highest age group mean was used as the mean control value for cervical lordosis.

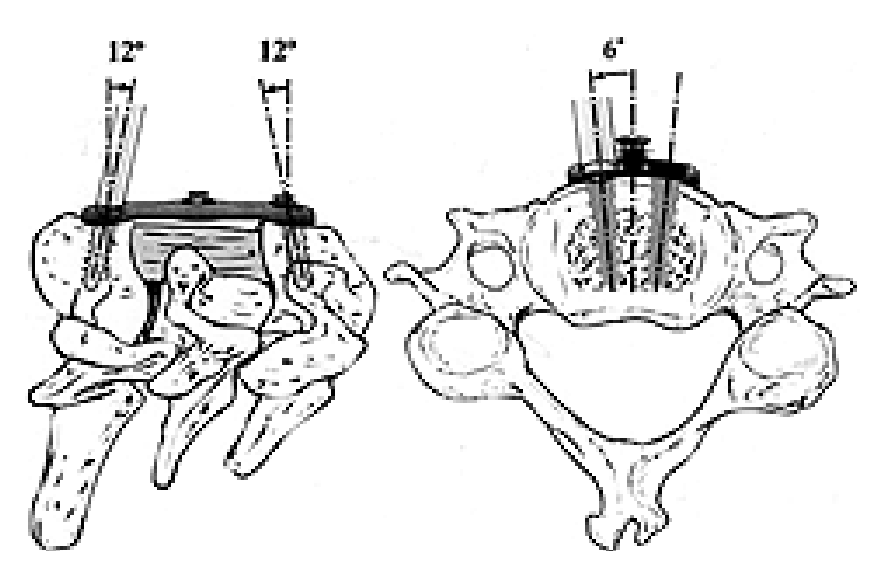

Fig. 2. Drawing depicting the screw angles of the fixed-screw construct.

Statistical analyses of age, percentage of smokers, mean time to follow up, satisfactory outcomes, and sex were performed using SPSS software and one-way ANOVA.

\section{RESULTS}

Table 1 summarizes the outcome data by procedure and construct type. Osseous fusion was shown in $72(93.5 \%)$ of 77 cases; overall outcome was satisfactory in $75 \%$ of patients. There was a statistically significant variation in smoking among the subgroups of patients: in those who underwent combined anterior-posterior procedures and those who underwent multilevel corpectomy a significantly higher rate of smoking was present compared with that found in the other groups ( $\mathrm{p}<0.05$, ANOVA).

There were no significant differences in age, sex, or in mean time to follow up among the five subgroups.

Satisfactory outcomes ranged from 63 to $91.6 \%$ among the subgroups, with a significantly lower rate of satisfactory outcome being shown in those who underwent combined anterior-posterior and multilevel ACDF procedures than other procedure types ( $p<0.05$, ANOVA).

There was no significant difference in fusion rates shown according to procedure or by construct type.

Analysis of the cervical lordosis demonstrated in asymptomatic patients compared with age-matched controls yielded a statistically significant difference in lordosis in all five categories; significantly less lordosis was present in treated patients than in controls $(p<0.05$, paired t-test). Segmental lordosis at the fusion levels was significantly less lordotic than overall cervical lordosis (as measured in the same patient) in three categories: singlelevel ACDF, multilevel ACDF, and combined anteriorposterior fusion ( $\mathrm{p}<0.05$, paired t-test).

There were two postoperative wound infections: one posterior, treated with washout and intravenous antibiotic agents; and one case of chronic anterior incision drainage in a case of a single-level ACDF, treated with washout and intravenous antibiotic agents.

There were two episodes of screw backout; neither caused symptoms and both were discovered on routine radiographic follow-up evaluation. Neither required operative intervention.

One patient who underwent single-level ACDF died of a cause unrelated to surgery 3 months after his operation. 


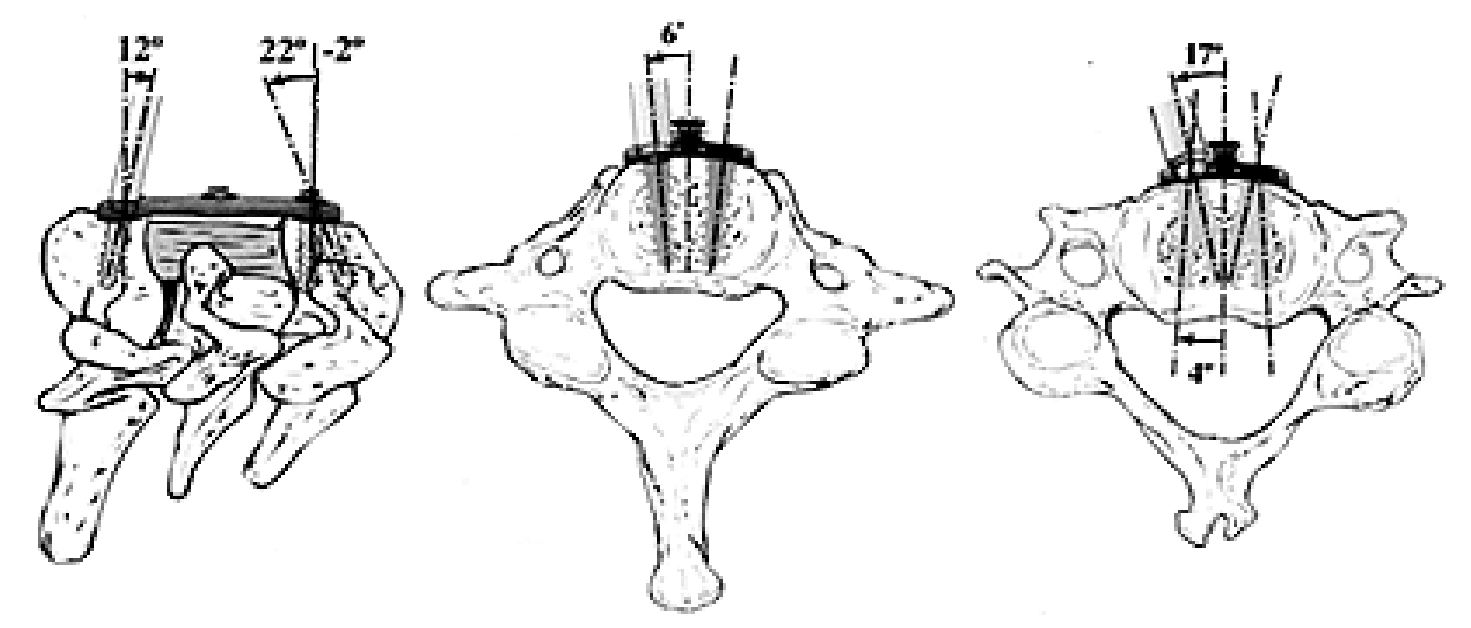

Fig. 3. Drawing depicting the screw angles of hybrid construct.

\section{DISCUSSION}

In most reviews, fusion rates range from 87.5 to $97 \%$ for anterior cervical procedures (both corpectomy and discectomy), in which plate and bone screw constructs are used to treat degenerative spondylosis. . $^{-5,8,8,11,18,19,23,25,32-34}$ The initial results obtained using the Atlantis cervical plating system seem to be comparable with those reported in most series, but the system provides the additional benefits of fixed, variable, and hybrid constructs, which we believe has allowed for a greater degree of tailoring of the Atlantis plate to individual patient needs.

The proliferation of ACP systems and subsequent results have elucidated both biomechanical advantages and disadvantages associated with each type of plating system. In general, we prefer to categorize ACPs as restrict-

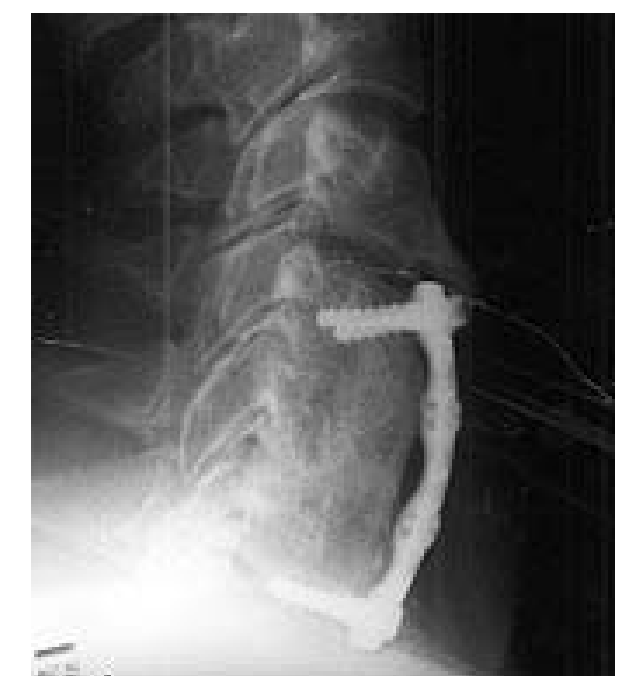

Fig. 4. Lateral radiograph obtained 14 months postoperatively, demonstrating construct settling after placement of the hybrid ACP for one-level corpectomy. The plate chosen for the construct is of a longer than optimal length, resulting in a reactive osteophyte in the anterior superior VB. In general, we use the shortest possible plate to avoid this phenomenon. ed backout and unrestricted backout systems, with the unrestricted backout systems representing those systems that require bicortical screw purchase because of the lack of screw-locking mechanisms. Examples of unrestricted backout systems include the Caspar and Morscher plate systems. $^{6-9,14,15,17,18,23}$ Hardware failure in ACP systems, defined as any broken or loosened screw or plate, ranges from 2 to $44 \%$ in unrestricted backout systems. ${ }^{6,19,22}$

Generally, lower hardware failure rates, ranging from 0 to $18 \%$, have been reported for restricted backout systems with unicortical locking screws, which provide greater screw pullout protection. ${ }^{19,30}$ Examples of restricted backout systems include the Synthes, Orion, and Codman plate systems. Although restricted backout systems were developed to improve the high rates of hardware failure demonstrated in cases in which unrestricted backout systems were used, the authors of many in vitro models and several clinical reports have advanced the idea that restricted backout systems allow the graft to be "shielded" from load bearing because the plate absorbs more of the load of the construct when screws are constrained from backing out. ${ }^{711,12,15,31}$ Thus, less compressive force may be sus-

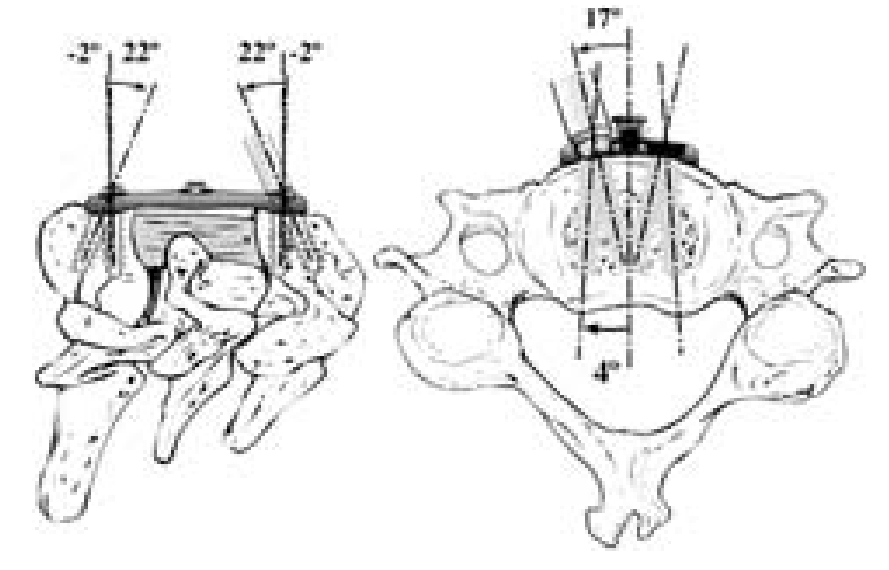

Fig. 5. Drawing showing the screw angles for the variablescrew construct. 


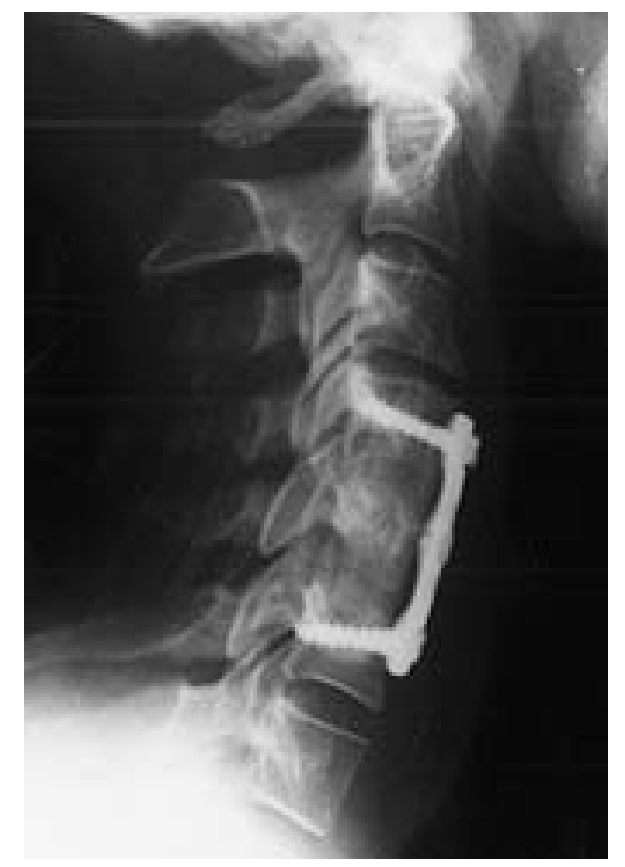

Fig. 6. Postoperative lateral radiograph obtained at 17 months, revealing excellent incorporation and fusion of fibular allograft in a case in which the hybrid ACP was implanted.

tained by the graft in restricted backout constructs; application of the law of Wolff to this situation would theoretically reduce the rate of fusion because there would be less compressive force on the graft.

As a result of concern about graft loading biomechanics, plate systems such as the Codman and Aline constructs have been developed. These plate systems allow for screws to rotate at the screw-plate interface, creating a semiconstrained system that allows for variable screw angulation, as well as less shielding of the graft by the plate.
The Atlantis plate is a restricted backout system with a floating washer design. The system has the option of fixed, variable, and hybrid constructs (Fig. 1). A fixed construct uses two or more sets of fixed-angle screws at a $12^{\circ}$ cephalad-caudad angle and a $6^{\circ}$ convergent (medial) angle (Fig. 2). We prefer the fixed construct for cases such as trauma that require rigid fixation. Biomechanically, the fixed construct is "constrained:" the fixed-angle locked screws permit no rotation or translation, creating a rigid fixation device. Screws may be bicortical if desired.

In the Atlantis hybrid construct two fixed-angle screws are used at the inferior portion of the construct at the aforementioned predetermined angles, whereas two variable-angle screws are used for the superior portion of the construct (Fig. 3). Screws placed between the fixed- and variable-angle screws are generally those of the variableangle type. Variable-angle screws can be directed from $22^{\circ}$ distal to $2^{\circ}$ proximal in a caudad-cephalad direction; variable screw angles range from a $17^{\circ}$ medial convergent to a $4^{\circ}$ lateral divergent angle. The resulting hybrid construct is semiconstrained, allowing for rotational pivoting at the screw-plate interface; the lower (fixed) screw acts as a "buttress." Because of the rotational pivoting, the overall construct undergoes "controlled subsidence," with increased load placed on the graft compared with that occurring in a constrained construct (Fig. 4). We use the hybrid construct in a majority of cases performed for cervical myelopathy and/or radiculopathy, because we believe that graft loading for this particular construct is optimum for most cases of degenerative cervical spondylosis.

The Atlantis variable construct illustrated in Fig. 5 uses entirely variable-angle screws at the range of angles previously mentioned. This construct is a semiconstrained system, which allows for rotational motion at the platescrew interface on both ends of the construct.

Fusion rates in our patients ranged from 90 to $100 \%$ for all subgroups; the mean rate was $93.5 \%$, which we consider to be comparable with most series of plate-related anterior cervical fusion procedures for myelopathy and/or
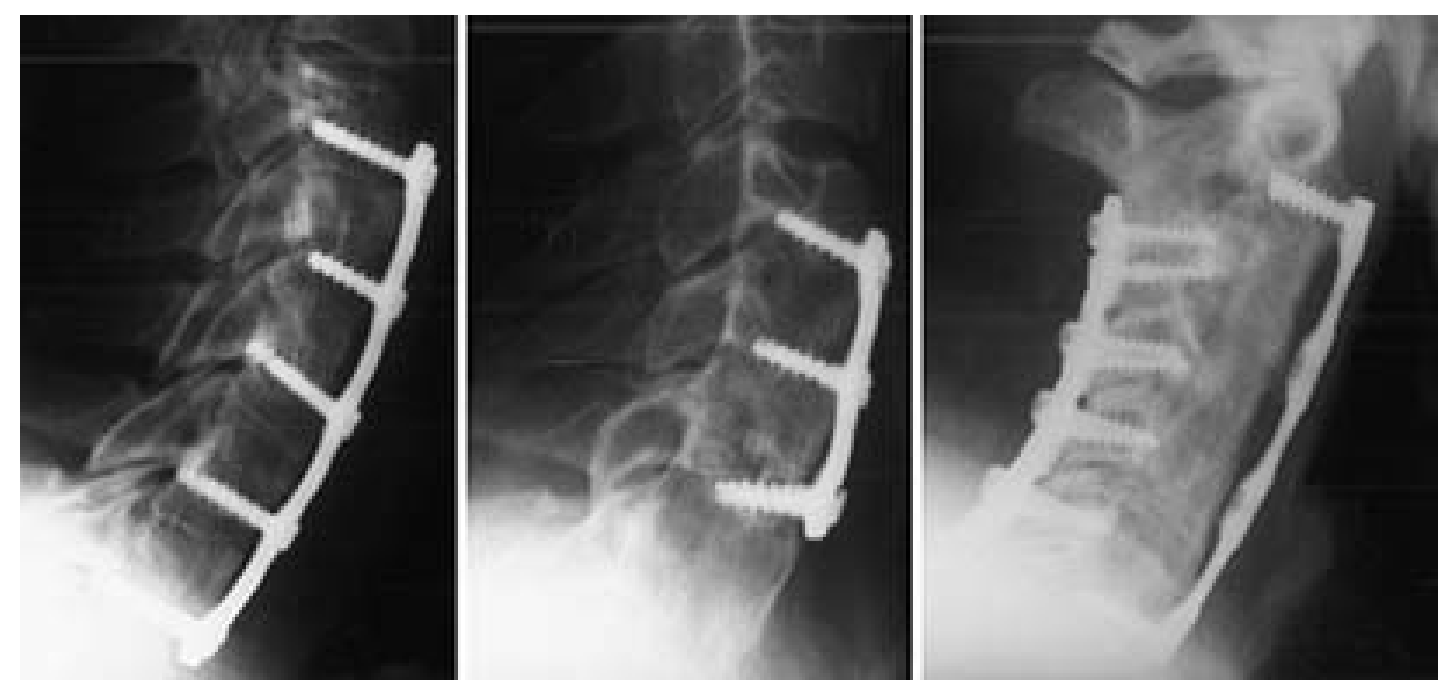

Fig. 7. Postoperative radiographs. Left: The hybrid ACP system, at 13 months after four-level ACDF. Center: The hybrid system, 15 months after two-level ACDF. Right: Twelve-month postoperative lateral radiograph, after multilevel corpectomy with posterior lateral mass plates. 
radiculopathy. 4,5,8,16,20,26,29 The mean fusion rate for singlelevel corpectomies in our series $(91.6 \%)$ compares favorably with a recent report of $87 \%$ in single-level corpectomy in which the Atlantis system was used (Fig. 6). ${ }^{11}$

Clinically, satisfactory outcomes were significantly worse in patients who had undergone multilevel ACDF procedures and combined anterior-posterior procedures, compared with other groups. We have not identified any factors that account for this difference (Fig. 7).

Our rate of hardware failure was $2.6 \%$ (two cases), and there were no episodes of plate breakage or graft extrusion. Both patients in whom screw failures occurred were asymptomatic, and no morbidity was associated with the two cases. The rate of hardware failure in this series is on the lower end of the 0 to $18 \%$ reported for all types of plate systems; in particular, an overall screw loosening rate of $2.4 \%$ has been reported in the literature. , $12,15,19,20,22^{2}$

The significance of reduced lordosis in all subgroups compared with age-matched asymptomatic controls can be attributed to the underlying degenerative cervical spondylotic disease. Although we believe that the Atlantis construct helps to restore cervical lordosis, preoperative radiographs were not available in a vast majority of cases, thereby obviating a statistically meaningful comparison of pre- and postoperative lordosis. The unavailability of preoperative radiographs is an unfortunate consequence of practicing at a tertiary referral center: many patients undergo their initial radiological studies at outside institutions. We can only conclude that after over 1 year mean follow up, significantly less lordsis was present in our patients than in age-matched controls.

Segmental lordosis was significantly reduced, compared with overall cervical lordosis, at follow up in three subgroups: those who had undergone single-level ACDF, multilevel ACDF, and single-level corpectomy. It seems logical that single-level constructs (that is, in corpectomy or discectomy) would not be lordotic compared with overall cervical lordosis, because the length of the construct covers only one level in the cervical spine. The finding that multilevel ACDF constructs are segmentally less lordotic than the overall cervical spine is more difficult to explain, although 14 of the 20 constructs were placed in two-level ACDF procedures. In our opinion, a two-level ACDF construct is essentially the same length as that used in a single-level corpectomy, and this fact can partially explain the lack of segmental lordosis demonstrated in the multilevel ACDF subgroup.

The significance of our findings of reduced overall lordosis and, in some cases, segmental lordosis is limited because preoperative radiographs were unavailable for comparison, although the authors of another study have found that ACP system can maintain lordosis. ${ }^{17}$

The results presented in this paper demonstrate the radiographic and clinical efficacy of the Atlantis ACP system at minimum 1-year follow up in 77 patients. We have found the flexibility of the Atlantis ACP system advantageous in tailoring anterior cervical constructs to individual patient biomechanical needs. There is a paucity of peerreviewed literature providing minimum 1-year follow-up data in cases in which a single ACP system is used; we hope to continue to follow our patients to extend our database and report long-term outcome data regarding the Atlantis system.

\section{Disclosure}

Doctors Haid and Rodts have significant financial interests in Medtronic Sofamor Danek.

\section{References}

1. Bailey R, Badgley C: Stabilization of the cervical spine by anterior fusion. J Bone Joint Surg Am 42:565-594, 1960

2. Bohler J, Gaudernak T: Anterior plate stabilization for fracturedislocations of the lower cervical spine. J Trauma 20: 203-205, 1980

3. Bose B: Anterior cervical fusion using Caspar plating: analysis of results and review of the literature. Surg Neurol 49:25-31, 1998

4. Bose B: Anterior cervical instrumentation enhances fusion rates in multilevel reconstruction in smokers. J Spinal Disord 14: 3-9, 2001

5. Caspar W, Barbier DD, Klara PM: Anterior cervical fusion and Caspar plate stabilization for cervical trauma. Neurosurgery 25:491-502, 1989

6. Caspar W, Geisler FH, Pitzen T, et al: Anterior cervical plate stabilization in one- and two-level degenerative disease: overtreatment or benefit? J Spinal Disord 11:1-11, 1998

7. Chen IH: Biomechanical evaluation of subcortical versus bicortical screw purchase in anterior cervical plating. Acta Neurochir 138:167-173, 1996

8. Connolly PJ, Esses SI, Kostuik JP: Anterior cervical fusion: outcome analysis of patients fused with and without anterior cervical plates. J Spinal Disord 9:202-206, 1996

9. DiAngelo DJ, Foley KT, Vossel KA, et al: Anterior cervical plating reverses load transfer through multilevel strut-grafts. Spine 25:783-795, 2000

10. Emery SE, Bohlman HH, Bolesta MJ, et al: Anterior cervical decompression and arthrodesis for the treatment of cervical spondylotic myelopathy. Two to seventeen-year follow-up. J Bone Joint Surg Am 80:941-951, 1998

11. Epstein NE: The management of one-level anterior cervical corpectomy with fusion using Atlantis hybrid plates: preliminary experience. J Spinal Disord 13:324-328, 2000

12. Epstein NE: The value of anterior cervical plating in preventing vertebral fracture and strut graft extrusion after multilevel anterior cervical corpectomy with posterior wiring and fusion: indications, results, and complications. J Spinal Disord 13:9-15, 2000

13. Gore DR, Sepic SB, Gardner GM: Roentgenographic findings of the cervical spine in asymptomatic people. Spine 11: $521-524,1986$

14. Griffith SL, Zogbi SW, Guyer RD, et al: Biomechanical comparison of anterior instrumentation for the cervical spine. J Spinal Disord 8:429-438, 1995

15. Grubb MR, Currier BL, Shih JS, et al: Biomechanical evaluation of anterior cervical spine stabilization. Spine 23:886-892, 1998

16. Kaiser MG, Haid RW Jr, Subach BR, et al: Anterior cervical plating enhances arthrodesis following discectomy anf fusion with cortical allograft. Neurosurgery (In press)

17. Katsuura A, Hukuda S, Imanaka T, et al: Anterior cervical plate used in degenerative disease can maintain cervical lordosis. J Spinal Disord 9:470-476, 1996

18. Kostuik JP, Connolly PJ, Esses SI, et al: Anterior cervical plate fixation with the titanium hollow screw plate system. Spine 18: 1273-1278, 1993

19. Lowery GL, McDonough RF: The significance of hardware failure in anterior cervical plate fixation. Patients with 2- to 7year follow-up. Spine 23:181-187, 1998

20. Mayr MT, Subach BR, Comey CH, et al: Cervical spinal stenosis: outcome after anterior corpectomy, allograft reconstruction, and instrumentation. J Neurosurg 96 (Spine 1):10-16, 2002 


\section{Atlantis anterior cervical plating system}

21. Odom GL, Finney W, Woodhall B: Cervical disk lesions. JAMA 166:23-28, 1958

22. Panjabi MM, Isomi T, Wang JL: Loosening at the screw-vertebra junction in multilevel anterior cervical plate constructs. Spine 24:2383-2388, 1999

23. Paramore CG, Dickman CA, Sonntag VK: Radiographic and clinical follow-up review of Caspar plates in 49 patients. J Neurosurg 84:957-61, 1996

24. Raveh J, Stich H, Sutter F, et al: Use of titanium-coated hollow screw and reconstruction plate system in bridging of lower jaw defects. J Oral Maxillofac Surg 42:281-294, 1984

25. Rechtine GR, Cahill DW, Gruerenberg M, et al: The synthes cervical spine locking plate and screw system in anterior cervical fusion. Tech Orthop 9:86-91, 1994

26. Schultz KD Jr, McLaughlin MR, Haid RW Jr, et al: Singlestage anterior-posterior decompression and stabilization for complex cervical spine disorders. J Neurosurg 93 (Spine 2): 214-221, 2000

27. Spivak JM, Chen D, Kummer FJ: The effect of locking fixation screws on the stability of anterior cervical plating. Spine 24: 334-338, 1999

28. Suh PB, Kosituk JP, Esses SI: Anterior cervical plate fixation with the titanium hollow screw plate system. A preliminary report. Spine 15:1079-1081, 1990

29. Swank ML, Lowery GL, Bhat AL, et al: Anterior cervical allograft arthrodesis and instrumentation: multilevel interbody grafting or strut graft reconstruction. Eur Spine J 6:138-143, 1997
30. Tominaga T, Koshu K, Mizoi K, et al: Anterior cervical fixation with the titanium locking screw-plate: a preliminary report. Surg Neurol 42:408-413, 1994

31. Ulrich C, Woersdoerfer O, Kalff R, et al: Biomechanics of fixation systems to the cervical spine. Spine 16 (Suppl 3):S4-S9, 1991

32. Wang JC, McDonough PW, Endow K, et al: The effect of cervical plating on single-level anterior cervical discectomy and fusion. J Spinal Disord 12:467-471, 1999

33. Wang JC, McDonough PW, Endow K, et al: Increased fusion rates with cervical plating for two-level anterior cervical discectomy and fusion. Spine 25:41-45, 2000

34. Wang JC, McDonough PW, Kanim LE, et al: Increased fusion rates with cervical plating for three-level anterior cervical discectomy and fusion. Spine 26:643-647, 2001

35. White AA III, Southwick WO, Deponte RJ, et al: Relief of pain by anterior cervical-spine fusion for spondylosis. A report of sixty-five patients. J Bone Joint Surg Am 55:525-534, 1973

Manuscript received November 16, 2001

Accepted in final form December 19, 2001.

Address reprint requests to: Bryan Barnes, M.D., Department of Neurosurgery, Suite 6400, 1365B Clifton Road, Northeast, Atlanta, Georgia. email: bbarn01@emory.edu. 